\title{
Chapter 15 \\ Common-Coil Dipole for a Very Large Hadron Collider
}

\author{
Alexander V. Zlobin
}

\begin{abstract}
A dipole magnet based on the common-coil design and pre-reacted $\mathrm{Nb}_{3} \mathrm{Sn}$ cable was developed at the Fermi National Accelerator Laboratory (FNAL) for a Very Large Hadron Collider. Three technological racetrack models and a short dipole model have been fabricated and tested. This chapter summarizes the main results of this program.
\end{abstract}

\subsection{Introduction}

In 1998 the Fermi National Accelerator Laboratory (FNAL) launched a new superconducting accelerator magnet research and development (R\&D) program with the goal to develop cost-effective and robust high field magnets and technologies for a post-Large Hadron Collider (LHC) machine. The collider concept discussed at that time was called the Very Large Hadron Collider (VLHC) (Fermilab 2001). It was based on a staged approach with $\sim 2$ T magnets in low-field Stage 1 and $\sim 10 \mathrm{~T}$ magnets in high-field Stage 2. Comprehensive studies of various magnet designs with small coil aperture, various coil cross-sections, cable parameters, etc., were performed to find optimal parameters and sound, affordable $\mathrm{Nb}_{3} \mathrm{Sn}$ dipole design suitable for VLHC Stage 2 with a nominal operating field of $10 \mathrm{~T}$.

One of the dipole designs, promoted at that time by Brookhaven National Laboratory (BNL) and Lawrence Berkeley National Laboratory (LBNL), was based on simple block-type racetrack coils arranged in a common-coil dipole configuration (Gupta 1997) (see also Chaps. 13 and 14). Although the commoncoil configuration is not the most efficient with respect to the required conductor amount, it has some attractive technological features. For example, the coil radii in this design are defined by the distance between apertures rather than by aperture size, making it suitable for brittle conductors such as $\mathrm{Nb}_{3} \mathrm{Sn}$.

As a part of FNAL high field accelerator magnet R\&D, a common-coil accelerator dipole with $\mathrm{Nb}_{3} \mathrm{Sn}$ coils was designed and fabricated using the react-and-wind

\footnotetext{
A. V. Zlobin (ه)

Fermi National Accelerator Laboratory (FNAL), Batavia, IL, USA

e-mail: zlobin@fnal.gov

(C) The Author(s) 2019 
$(\mathrm{R} \& \mathrm{~W})$ method. The main results of this work are presented in this chapter. It includes design studies and analyses of the common-coil dipole concept, as well as magnet design, fabrication technology, and specific features and parameters of the first accelerator quality $\mathrm{Nb}_{3} \mathrm{Sn}$ common-coil dipole. This magnet has many innovative design and technological features, such as single layer coils, a 60-strand Rutherford cable with large aspect ratio, and stainless-steel collars reinforced by horizontal bridges between coil blocks. The chosen collar structure required simultaneous winding of both left and right coils into the collar structure and impregnating the coil with epoxy inside this structure. Test results of the $\mathrm{Nb}_{3} \mathrm{Sn}$ common-coil dipole model are reported and discussed. The broader R\&D challenges, including studies and selection of strand and cable as well as fabrication and tests of practice coils and racetrack magnets, are also presented and discussed.

\subsection{Magnet Design and Analysis}

Several common-coil dipole designs suitable for VLHC were studied in the late 1990s and the early 2000s at FNAL (Ambrosio et al. 2000a; Sabbi et al. 2000). A common feature of all those designs was a multi-layer, multi-block coil based on Rutherford cables. Design analysis revealed serious mechanical difficulties in those designs, in particular large deformations of coils and support structures during magnet excitation, and high stresses in the coil and the support structure. To resolve these problems, a design with a horizontally split yoke was proposed (Ambrosio et al. 2001). Although this design allowed the reduction of stresses in the coils, it complicated the yoke configuration and assembly. This design option ultimately led to complex magnet fabrication process, and eliminated the main advantage of the common-coil design concept-its simplicity.

To avoid these problems, a single-layer common-coil dipole with a strong internal support structure was also developed at FNAL (Kashikhin and Zlobin 2001a). This design maintained all of the advantages of the common-coil approach, including the option of using the R\&W method, and also provided aperture size, maximum field, field quality, and coil volume comparable to a corresponding cos-theta dipole design.

\subsubsection{Magnetic Design}

\subsubsection{Single-Layer Coil}

The cross-section of the single-layer coil developed at FNAL for a common-coil dipole is presented in Fig. 15.1. Each coil contains 56 turns combined into three blocks and divided by $6 \mathrm{~mm}$ thick spacers. There are also two $3 \mathrm{~mm}$ thick spacers in each central block. The pole blocks are displaced horizontally by $5 \mathrm{~mm}$ with respect 


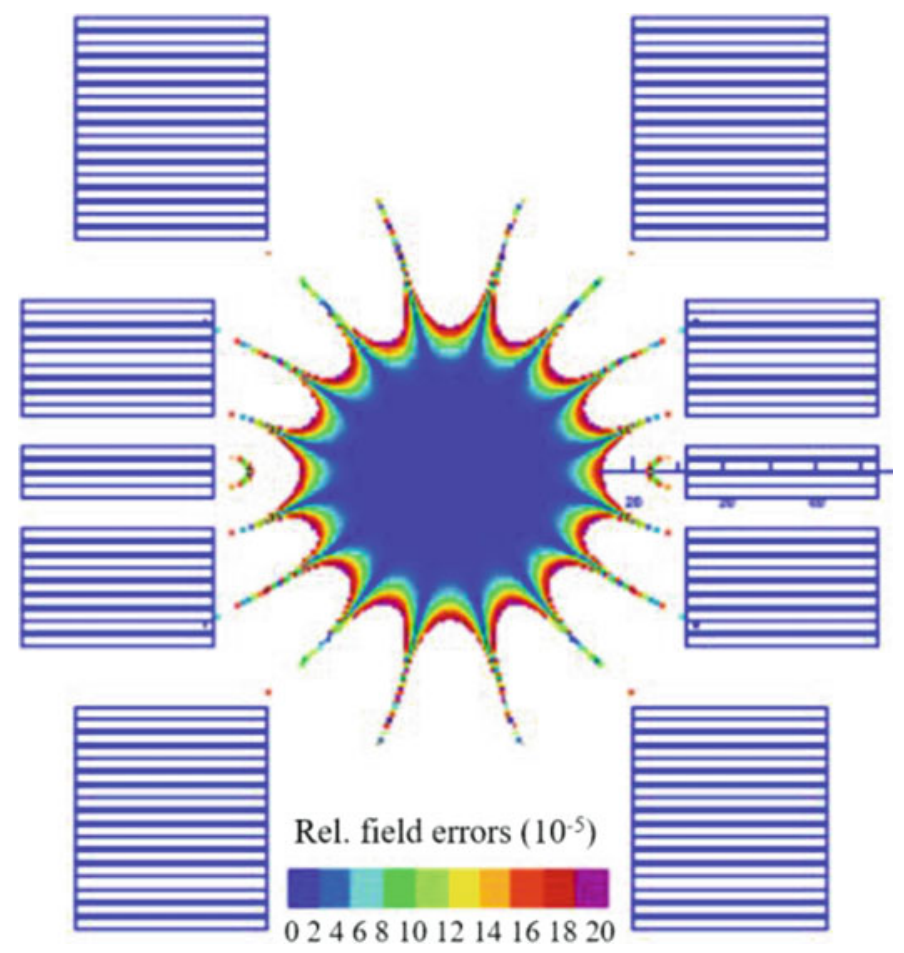

Fig. 15.1 Single-layer coil for a common-coil dipole

to the central blocks. The size and position of blocks and spacers were optimized using the ROXIE computer program (Russenschuck 1995) to achieve the maximum transfer function, minimum coil volume, and small low-order geometrical harmonics. The gap of $40 \mathrm{~mm}$ between pole blocks defines the diameter of the coil apertures.

The coil uses $21.09 \mathrm{~mm}$ wide and $1.245 \mathrm{~mm}$ thick rectangular Rutherford cable made of 60 strands of $0.7 \mathrm{~mm}$ diameter. The cable insulation thickness is $0.10 \mathrm{~mm}$. Based on bending degradation studies described below, to use a reacted cable with the chosen strand size, the minimal coil radius must be about $90 \mathrm{~mm}$, which defines the minimal aperture separation in this common-coil dipole.

\subsubsection{Cold Iron Design}

Figure 15.2 shows the initial cross-section of a single-layer common-coil dipole with cold iron. Two coils surrounded by the mechanical support structure are placed inside the round iron separated vertically into two pieces. The gap between the iron pieces is always open to ensure contact of the collared coil with the iron after cooling to operating temperature. Special holes in the iron blocks and magnetic inserts are 
Fig. 15.2 Common-coil dipole concept with cold iron

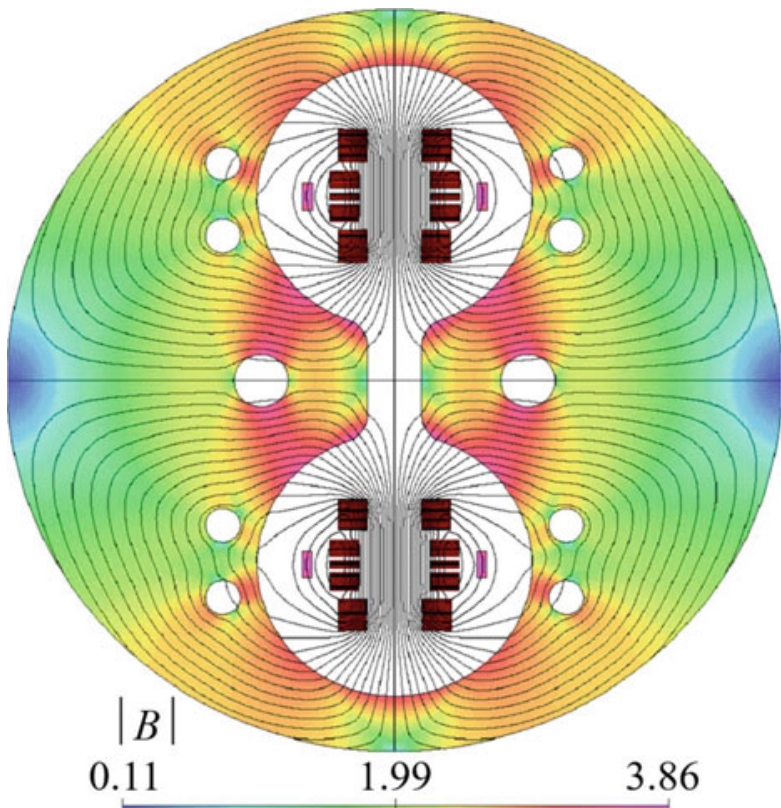

used to reduce the iron saturation effect. The iron inner surface, outer radius, and the geometry and position of the correction holes and inserts were optimized to achieve good field quality and the appropriate transfer function, and to minimize fringe fields and iron size.

Due to the asymmetry of the iron with respect to the horizontal plane of the magnet apertures, there is a skew quadrupole component $a_{2}$ of -7 units $\left(10^{-4}\right.$ relative to the dipole field at a reference radius of $10 \mathrm{~mm}$ ). This skew quadrupole component was suppressed by shifting the top and bottom coil blocks by $\sim 0.5 \mathrm{~mm}$ with respect to the coil mid-planes of each aperture. The optimized iron outer diameter (OD) is $564 \mathrm{~mm}$ and the aperture separation is $280 \mathrm{~mm}$.

\subsubsection{Warm Iron Design}

Figure 15.3 shows a cross-section of the single-layer common-coil dipole with warm iron. To compensate for the decrease of the magnet transfer function and the maximum field in this design, the number of turns in the coil was increased from 56 to 61 . Magnetic coupling between apertures in this design produces a skew quadrupole component $a_{2}$ as large as -35 units. Some small horizontal and vertical displacements of the coil blocks, of less than $0.5 \mathrm{~mm}$, allowed canceling of this component. The effect of iron saturation on the field harmonics was reduced by optimizing the iron inner and outer diameters. The optimal values of the iron OD and thickness in this design were $710 \mathrm{~mm}$ and $55 \mathrm{~mm}$, respectively. 
Fig. 15.3 Common-coil dipole concept with warm iron

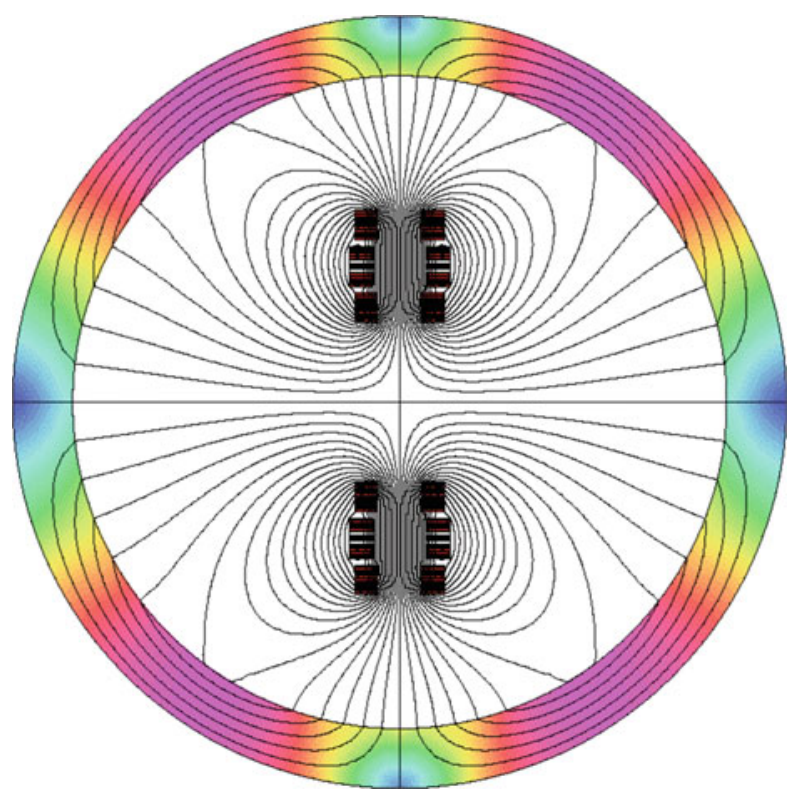

Table 15.1 Calculated common-coil dipole parameters

\begin{tabular}{l|l|l}
\hline & Cold iron & Warm iron \\
\hline Aperture diameter $(\mathrm{mm})$ & 40 & 40 \\
\hline Aperture separation $(\mathrm{mm})$ & 280 & 280 \\
\hline Iron outer diameter $(\mathrm{mm})$ & 564 & 710 \\
\hline Max. bore field $(\mathrm{T})$ & 10.75 & 10.69 \\
\hline Max. quench current $(\mathrm{kA})$ & 24.5 & 25.4 \\
\hline Stored energy at $11 \mathrm{~T}(\mathrm{~kJ} / \mathrm{m})$ & 880 & 956 \\
\hline Inductance at $11 \mathrm{~T}(\mathrm{mH} / \mathrm{m})$ & 2.78 & 2.74 \\
\hline Coil area $\left(\mathrm{cm}^{2}\right)$ & 53.4 & 58.2 \\
\hline
\end{tabular}

\subsubsection{Magnet Parameters}

The main parameters of the common-coil dipoles with cold and warm iron are shown in Table 15.1. The maximum bore field $B_{\max }$ was calculated for a cable packing factor of $0.88, \mathrm{a} \mathrm{Cu} /$ non-Cu ratio of 0.85 , and a cable critical current density $J_{\mathrm{c}}(12 \mathrm{~T}, 4.2 \mathrm{~K})$ of $2 \mathrm{kA} / \mathrm{mm}^{2}$.

The maximum field in the magnet aperture at $4.2 \mathrm{~K}$ vs. the critical current density of the superconductor in the coil is shown in Fig. 15.4. Assuming $10 \% J_{\mathrm{c}}$ degradation during coil fabrication, to provide the nominal operating field of $10 \mathrm{~T}$ with $15 \%$ margin, the designs described need $\mathrm{Nb}_{3} \mathrm{Sn}$ strands with a rather high $J_{\mathrm{c}}(12 \mathrm{~T}, 4.2 \mathrm{~K})$ of $3 \mathrm{kA} / \mathrm{mm}^{2}$ and a $\mathrm{Cu} / \mathrm{non}-\mathrm{Cu}$ ratio of 1.2 . 


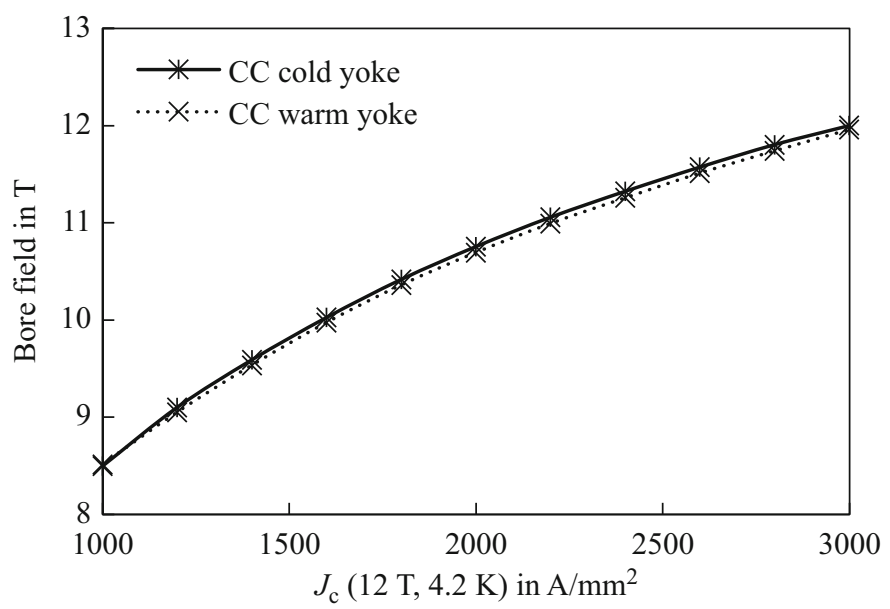

Fig. 15.4 Maximum field in the magnet aperture at $4.2 \mathrm{~K}$ vs. the critical current density $J_{\mathrm{c}}(12 \mathrm{~T}, 4.2 \mathrm{~K})$ of superconductor in the coil

Table 15.2 Geometrical harmonics at $R_{\text {ref }}=10 \mathrm{~mm}$ in $10^{-4}$

\begin{tabular}{l|l|l|l|l}
\hline \multirow{2}{*}{ Harmonic number } & \multicolumn{2}{l|}{ Cold iron } & \multicolumn{2}{l}{ Warm iron } \\
\cline { 2 - 5 } & $a_{n}$ & $b_{n}$ & $a_{n}$ & $b_{n}$ \\
\hline 2 & 0.005 & - & 0.000 & - \\
\hline 3 & - & 0.000 & - & -0.005 \\
\hline 4 & -0.001 & - & 0.002 & - \\
\hline 5 & - & -0.001 & - & -0.001 \\
\hline 6 & -0.002 & - & -0.003 & - \\
\hline 7 & - & -0.001 & - & -0.032 \\
\hline 8 & 0.011 & - & -0.128 & - \\
\hline 9 & - & -0.046 & - & -0.059 \\
\hline 10 & 0.003 & - & -0.004 & - \\
\hline & & & &
\end{tabular}

The field in the aperture of accelerator magnets is represented in terms of harmonic coefficients defined by the formula

$$
B_{y}+i B_{x}=B_{1} \sum_{n=1}^{\infty}\left(b_{n}+i a_{n}\right)\left(\frac{x+i y}{R_{\mathrm{ref}}}\right)^{n-1}
$$

where $B_{x}$ and $B_{y}$ are horizontal and vertical transverse field components, $B_{1}$ is the dipole field strength, and $b_{n}$ and $a_{n}$ are the $2 n$-pole coefficients at a reference radius $R_{\text {ref. The normal }} b_{n}$ and skew $a_{n}$ harmonic coefficients are expressed in units of $10^{-4}$ parts of the main dipole field $B_{1}$.

The calculated geometrical harmonics at $R_{\text {ref }}=10 \mathrm{~mm}$ for the common-coil dipoles with cold and warm iron are presented in Table 15.2. 
It can be seen that both common-coil dipole designs after optimization have very small geometrical field harmonics. Analysis showed that the design with warm yoke tolerates a coil-to-yoke misalignment of up to $2 \mathrm{~mm}$ without noticeable deterioration of field quality and overload of the magnet support system.

It was possible to suppress the effect of iron saturation on the skew quadrupole $a_{2}$ and normal sextupole $b_{3}$ in both designs up to $12 \mathrm{~T}$. The calculated reduction of the magnet transfer function in the cold iron design reached $\sim 10 \%$ at the bore field of $12 \mathrm{~T}$, whereas there was no iron saturation effect on the magnet transfer function for the warm iron design.

Note that contrary to twin-aperture dipole magnets with a horizontal bore arrangement (Kashikhin and Zlobin 2001a) (see also Chap. 7), the common-coil dipole design with warm iron does not have any advantage relative to the common-coil dipole with cold iron, besides the absence of the iron saturation effect.

\subsubsection{Mechanical Design}

\subsubsection{Structure Concept}

In a common-coil dipole design the two apertures are positioned vertically. This layout requires a rather thick skin (significantly thicker than in designs with a horizontal aperture layout), since the horizontal components of the Lorentz force in each coil are added. The described single-layer coil with current blocks separated by relatively large spacers allows the use of a coil support structure with stress management. This reduces the Lorentz force transferred to the skin (Novitski et al. 2001) and, thus, the skin thickness.

Fig. 15.5 Cross-section of the single-layer commoncoil dipole

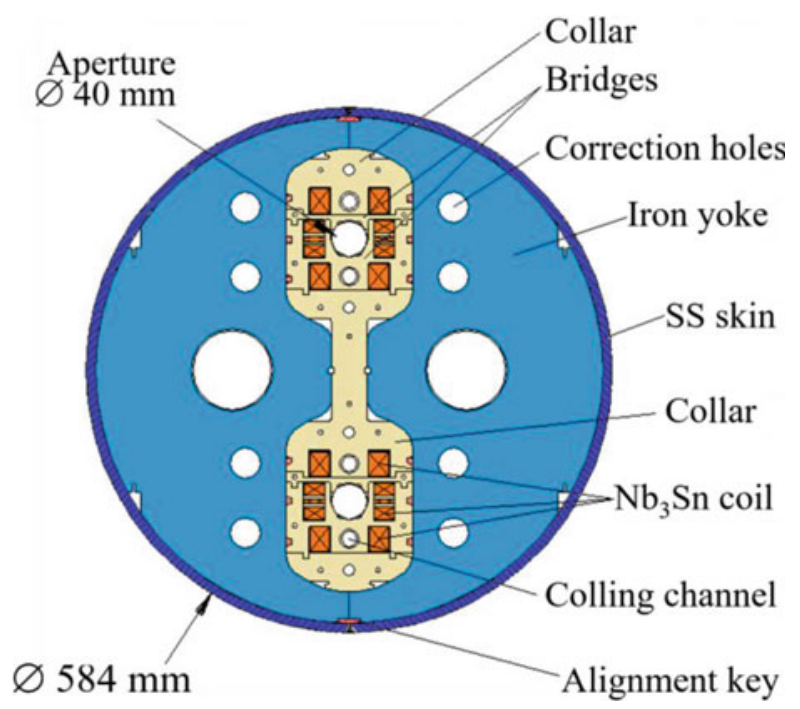


The cross-section of the optimized single-layer common-coil dipole with cold iron yoke and special collars (HFDC series) is shown in Fig. 15.5. The collar is common for both apertures to simplify coil winding and collared coil handling. The collar structure has rectangular windows for the coil blocks, and round holes for the beam pipes and cooling channels. During magnet yoking and skinning it protects the coil from the horizontal and vertical over-compression. In operation, the structure prevents transferring the vertical Lorentz forces from the pole blocks to the coil central blocks. It also captures a substantial part of the horizontal Lorentz forces in the coils, thereby reducing the force applied directly to the yoke and skin.

The collared coil is located inside the vertically split iron yoke, which is itself enclosed in a stainless-steel skin. The vertical pre-stress of the coils is supplied by the collars. The horizontal pre-compression of the collared coil is produced by the stainless-steel skin through the iron yoke. Thick end plates welded to the skin restrict the axial coil motion under the Lorentz forces.

The described design implies some obvious fabrication steps and conditions. Specifically, both coils have to be wound concurrently and directly into the coil support structure. To do this, the collar is divided into several parts (see Fig. 15.5) that are locked together with keys. After winding, the collared coil assembly is impregnated with epoxy, which produces a very strong mechanical structure. Mold release is used on the coil-collar interfaces for shear stress relief.

\subsubsection{Mechanical Analysis}

Mechanical analysis was performed to validate the design concept of the magnet support structure, optimize the structure dimensions, and choose the materials (Novitski et al. 2001). The main goal of the analysis was to keep the maximum stress in the coil below $150 \mathrm{MPa}$ under all conditions, limit turn displacements by $0.1 \mathrm{~mm}$ in a field range up to $11 \mathrm{~T}$, and provide operation of the structure in the elastic regime.

A 2D ANSYS (ANSYS Inc., Canonsburg, PA) model, which included the coil blocks surrounded by $0.5 \mathrm{~mm}$ thick polyimide insulation, the stainless-steel coil support structure with $20 \mathrm{~mm}$ wide collars, the iron yoke, and the $10 \mathrm{~mm}$ thick stainless-steel skin, was created. The thermal and mechanical properties of the materials used in the model are reported by Chichili et al. (2000). Since the coil is impregnated inside the support structure at low compression, the value of the coil modulus of elasticity used in the calculation was $20 \mathrm{GPa}$.

Calculations were performed for both aluminum and stainless-steel collars. The main benefit of the aluminum collar is its large thermal contraction, which increases the coil pre-stress after cooling down. The analysis revealed, however, that the peak equivalent stress in the aluminum collar exceeds the material yield stress by a factor of two for the chosen collar dimensions. To reduce the stress, a substantial increase of the collar size would have been necessary. The calculated distributions of the equivalent stress in the coil with stainless-steel collars after assembly, after cooling down and at the design field of $11 \mathrm{~T}$, are shown in Fig. 15.6. 
a

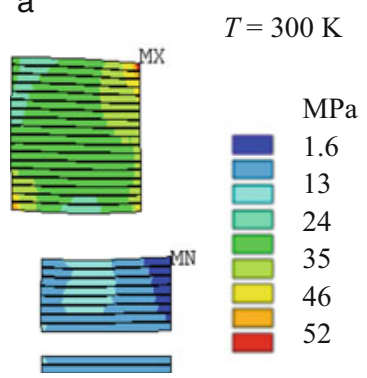

b

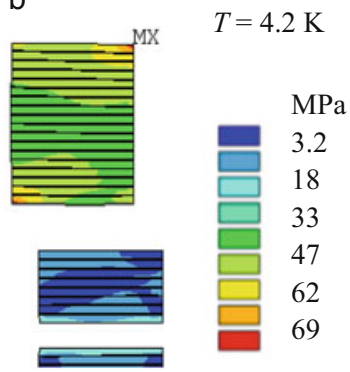

C

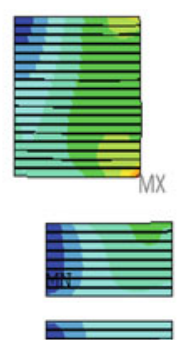

$B=11 \mathrm{~T}$

$\mathrm{MPa}$

4.8

33

61

90

118

132

Fig. 15.6 Distributions of the equivalent stress in MPa in the coil quadrant: (a) after assembly $(300 \mathrm{~K})$; (b) after cool-down $(4.2 \mathrm{~K})$; and (c) at a bore field of $11 \mathrm{~T}$

Table 15.3 Equivalent stress in coil and support structure

\begin{tabular}{l|l|l|l|l|l}
\hline Stage & Coil $(\mathrm{MPa})$ & Bridges $(\mathrm{MPa})$ & Collar $(\mathrm{MPa})$ & Yoke $(\mathrm{MPa})$ & Skin $(\mathrm{MPa})$ \\
\hline $300 \mathrm{~K}$ & 52 & 118 & 361 & 99 & 125 \\
\hline $4.2 \mathrm{~K} / 0 \mathrm{~T}$ & 69 & 178 & 408 & 194 & 327 \\
\hline $4.2 \mathrm{~K} / 11 \mathrm{~T}$ & 132 & 533 & 455 & 152 & 358 \\
\hline
\end{tabular}

At $300 \mathrm{~K}$, the pole blocks are preloaded nearly uniformly in vertical and horizontal directions, whereas the center blocks have a lower, mostly vertical preload. At $4.2 \mathrm{~K}$ and maximum Lorentz force, there is no stress on the inner coil-collar interface, while on the outer interface it is large and nearly equally distributed. Analysis shows that the collar structure described intercepts half of the horizontal Lorentz force and prevents transfer of the vertical Lorentz force from the pole to the center blocks.

The stress distribution in the yoke is not uniform. The highest stress is near the collar-yoke interface. The radial force on the yoke-skin interface is uniform, leading to a homogeneous azimuthal stress distribution in the skin. The maximum equivalent stresses in all parts of the magnet are less than the target design values under all conditions.

For the case of glued coil-to-collar interfaces, the coil shape practically follows the shape of the support structure, and the coil displacements are rather small. However, the shear stress on some coil surfaces exceeds $50 \mathrm{MPa}$, which is critical for epoxy bonding that has a shear strength of $30 \mathrm{MPa}$ (Ohira and Nishijima 2000). Therefore, a stress-relief layer is needed, particularly on the inner and top surfaces of the pole and center blocks. With a sliding coil-collar interface, the horizontal block displacements are less than $0.07 \mathrm{~mm}$, independently from the coil pre-stress. A small vertical coil pre-stress of $30 \mathrm{MPa}$ reduces vertical movements of the pole-block top surface to $0.03-0.04 \mathrm{~mm}$, which is tolerable from the viewpoint of variation of field harmonics in the operating cycle, but may still impact the magnet quench performance.

Table 15.3 presents the calculated equivalent stress in the magnet coil and the support structure at different assembly and operating stages. It can be seen that the target stress and displacement limits are satisfied in this design. 


\subsection{R\&W Common-Coil Dipole R\&D}

A special $R \& W$ R\&D program in support of the single-layer common-coil dipole was performed at FNAL in collaboration with LBNL (Ambrosio et al. 2000b, 2002a, b, 2003, 2004a; Bauer et al. 2001). It included the following steps:

1. Wire and cable $R \& D$ for the $R \& W$ technology;

2. Technology development using sub-scale cable, flat racetrack coils and simple bolted structures;

3. Fabrication and test of a short mechanical model;

4. Fabrication of a full-scale technological model.

\subsection{1 $\mathrm{Nb}_{3} \mathrm{Sn}$ Wire and Cable $\mathrm{R} \& \mathrm{D}$}

The $\mathrm{R} \& \mathrm{~W}$ technology requires the use of $\mathrm{Nb}_{3} \mathrm{Sn}$ cables with thin strands to reduce the $I_{\mathrm{c}}$ degradation due to the bending of reacted cable. On the other hand, the target design field of $10 \mathrm{~T}$ requires a relatively wide cable for the single-layer dipole. A $21 \mathrm{~mm}$ wide Rutherford cable with 60 strands of $0.7 \mathrm{~mm}$ diameter meets both requirements. Such a cable has an aspect ratio of $\sim 18$, which was noticeably larger than most state-of-the-art cables. Fabrication of this cable required equipment that at the time was available only at LBNL.

A first cabling run was performed at LBNL in September 2000 using internal tin (IT) $\mathrm{Nb}_{3} \mathrm{Sn}$ wires developed for the International Thermonuclear Experimental Reactor (ITER) project. The wires were drawn down to a nominal diameter of $0.7 \mathrm{~mm}$. The assessment of this cable at FNAL showed that it could be reacted and then wound into racetrack type coils. Moreover, measurements of strands extracted from the cable confirmed that the $I_{\mathrm{c}}$ degradation due to the cabling was relatively small, approximately $10 \%$. Two subsequent runs to produce long cable lengths were then performed. The first run used IT wires produced by Intermagnetics General Corporation (IGC), and the second run used modified jellyroll (MJR) wires produced by Oxford Superconducting Technologies (OST).

To evaluate the expansion of the cable cross-section after reaction, the two different cables were measured in free conditions before and after reaction. It was found that the width of the IT cable increased by $0.7 \%$ and the cable thickness increased by $3 \%$, whereas the MJR cable increased by $1.6 \%$ in both dimensions.

The conductor R\&D program also included studies of $I_{\mathrm{c}}$ degradation of various wire types and diameters, fabrication of cables with and without a stainless-steel core, and measurement of cable $I_{\mathrm{c}}$ degradation due to bending and transverse pressure after bending. The main outcome of the studies was that using synthetic oil during cabling avoided strands sticking during cable reaction, and therefore reduced $I_{\mathrm{c}}$ degradation due to cable bending. The cables with a stainless-steel core, however, which is used to suppress eddy currents in cables, demonstrated larger $I_{\mathrm{c}}$ degradation in cable bending experiments. 


\subsubsection{Single-Layer Racetracks}

To develop procedures (including coil impregnation inside the magnet structure) and select an appropriate cable insulation design and material for the $\mathrm{R} \& \mathrm{~W}$ common-coil dipole, simple single-layer racetrack magnets (HFDB series) based on sub-sized pre-reacted cable were built and tested. The racetrack magnet consisted of two flat racetrack coils (Fig. 15.7) connected in the common-coil configuration, and a bolted mechanical structure without an iron yoke (Fig. 15.8).

The cable had $41 \mathrm{Nb}_{3} \mathrm{Sn}$ strands, each $0.7 \mathrm{~mm}$ in diameter, and a rectangular cross-section of $15.05 \mathrm{~mm}$ width and $1.218 \mathrm{~mm}$ thickness. The racetrack mechanical structure included two thick main plates connected by fifty seven $25.4 \mathrm{~mm}$ diameter bolts, and two side and two end pushers bolted to the main plates with smaller bolts. The side and end pushers provided the initial coil pre-stress inside the structure. The racetrack magnet parameters are summarized in Table 15.4.

Each racetrack coil was $730 \mathrm{~mm}$ long and had a $400 \mathrm{~mm}$ long straight section. The minimal cable bending radius in the coil was $90 \mathrm{~mm}$. Each coil end had one spacer, whereas there were no spacers in the coil straight section. All the parts inside the coil were made of G10 and the end shoes were made of bronze. Fiberglass sheets were placed on each side of the coil. Two coils inside the mechanical structure were separated by a $5 \mathrm{~mm}$ thick G10 plate. All the structure parts (main plates, side and end pushers) were made of stainless steel.

Three racetrack magnets of HFDB series were fabricated and tested at FNAL from 2001 to 2003.

a

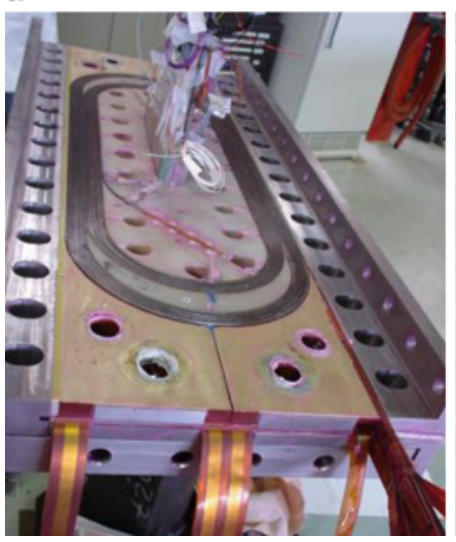

b

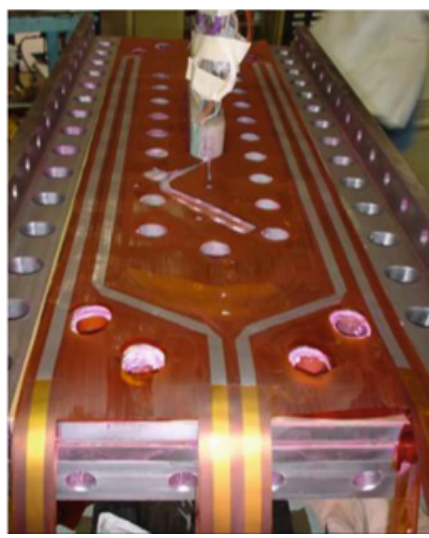

Fig. 15.7 (a) A single-layer racetrack coil after winding is being installed into the support structure (HFDB02). Each coil end has one spacer, whereas no spacers in the coil straight section were used. All parts inside the coil are made of G10. The end shoes are split in two pieces and are made from bronze. (b) Quench protection heaters are installed on both sides of the coil 
Fig. 15.8 Racetrack mechanical structure (lead end). Two thick main plates are connected by 57 bolts, and two side and two end pushers are bolted to the main plates

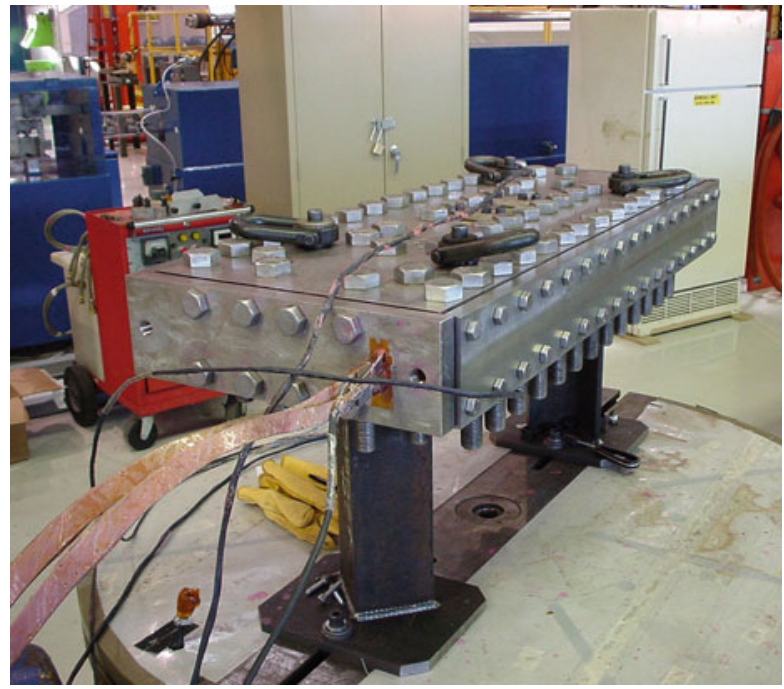

Table 15.4 Racetrack design parameters

\begin{tabular}{l|l}
\hline Parameter & Value \\
\hline Gap between coils (mm) & 5 \\
\hline Number of turns per coil & 29 \\
\hline Minimum radius in the ends (mm) & 90 \\
\hline Transfer function (T/kA) & 0.625 \\
\hline Inductance (mH) & 0.33 \\
\hline Stored energy at 9 T $(\mathrm{kJ})$ & 34.3 \\
\hline Normal horizontal force at 9 T $(\mathrm{MN})$ & 1.8 \\
\hline
\end{tabular}

\subsubsection{HFDB01}

This magnet used IT $\mathrm{Nb}_{3} \mathrm{Sn}$ wire produced by IGC. The wire had 19 sub-elements surrounded by a tantalum barrier. The $\mathrm{Cu} /$ non- $\mathrm{Cu}$ ratio was 0.61 . The effective filament diameter was large, $\sim 0.176 \mathrm{~mm}$, and together with the low $\mathrm{Cu} / \mathrm{non}-\mathrm{Cu}$ ratio, it was suspected to be the cause of conductor instabilities at fields below $13 \mathrm{~T}$.

The cable was fabricated at LBNL and heat treated at FNAL using the following four-step schedule: $215^{\circ} \mathrm{C}$ for $175 \mathrm{~h}, 340^{\circ} \mathrm{C}$ for $120 \mathrm{~h}, 575^{\circ} \mathrm{C}$ for $160 \mathrm{~h}$, and $700{ }^{\circ} \mathrm{C}$ for $30 \mathrm{~h}$. Steps 2 and 3 were introduced to prevent tin leaks during cable heat treatment. The duration of step 4 was reduced in an unsuccessful attempt to improve the conductor stability at $10 \mathrm{~T}$. The $I_{\mathrm{c}}$ degradation at $12 \mathrm{~T}$ due to cabling was $\sim 16 \%$.

Magnet tests revealed a large reduction of $39 \%$ of the magnet quench current with respect to the maximum current estimated from short sample data. Many voltage spikes were observed during the current ramp up. 


\subsubsection{HFDB02}

This magnet had several new features, including a different wire, cable insulation, and new techniques of cable insulation and coil winding. The Rutherford cable was made of wires produced by OST using the MJR process with 54 sub-elements and $46.5 \%$ copper. Samples of round wire, reacted with the cable, had a critical current of $1.87 \mathrm{kA} / \mathrm{mm}^{2}$ at $12 \mathrm{~T}$ and $4.2 \mathrm{~K}$. The measured $I_{\mathrm{c}}$ degradation due to cabling was only $2 \%$. The calculated maximum field in the coil at $4.5 \mathrm{~K}$ was $10.2 \mathrm{~T}$ at $16.87 \mathrm{kA}$. Coils were wound inside the mechanical structure and impregnated in situ. Polyimide films with mold release were used to avoid coils sticking to the mechanical structure.

The magnet reached $7.7 \mathrm{~T}$, which corresponded to $78 \%$ of the expected short sample limit. The highest quench current of $12.68 \mathrm{kA}$ was reached at a ramp rate of $75 \mathrm{~A} / \mathrm{s}$, showing a reduction of magnet quench currents at both lower and higher current ramp rates. An unusual correlation was also seen between temperature and quench current. Instead of increasing, magnet quench current monotonically decreased when the helium bath temperature decreased from 4.5 to $1.9 \mathrm{~K}$.

\subsubsection{HFDB03}

Based on the HFDB02 results, some of the fabrication steps were further improved. A gap was introduced between the innermost cable turn and the core of the reaction spool. Some voltage taps were made of $0.05 \mathrm{~mm}$ thick brass strips instead of copper wires. An appropriate cable support was provided at all stages of the coil winding. Eight instrumented end bullets with resistive strain gauges, as opposed to four in HFDB02, and capacitance gauges in the coil straight sections, were used to monitor coil stresses. The instrumented side bolts were placed according to the locations of peak loads, as identified by the finite element analysis.

The HFDB03 short sample limits at $4.5 \mathrm{~K}$ were $10.06 \mathrm{~T}$ and $16.59 \mathrm{kA}$. The maximum quench current was $12.59 \mathrm{kA}$, or $76 \%$ of the expected short sample limit. The ramp rate dependence again had a positive slope at low ramp rates, with a peak at $300 \mathrm{~A} / \mathrm{s}$. The dependence of magnet quench current vs. temperature was flat.

Fabrication and tests of HFDB racetrack magnets allowed the development of many aspects of the $\mathrm{R} \& \mathrm{~W}$ technology, such as reaction of long cable lengths without strand sintering, cable co-winding with insulation, coil in situ impregnation with epoxy, and coil preload. Magnet quench performance studies did not, however, provide clear answers on the poor conductor performance in these magnets. As understood later (Zlobin et al. 2006), the quench performance of a majority of $\mathrm{Nb}_{3} \mathrm{Sn}$ magnets tested at FNAL in the early 2000 was significantly limited by flux jump instabilities in the $\mathrm{Nb}_{3} \mathrm{Sn}$ wires. 


\subsubsection{HFDC Mechanical Model}

The mechanical model of the common-coil dipole consisted of a $165 \mathrm{~mm}$ long slice of magnet straight section. It was assembled and tested to validate magnet assembly procedures and compare the results of mechanical tests with the predictions of mechanical analyses. The mechanical model typically includes all components of the dipole straight section, i.e., coils, collars, yoke, and skin. Coil blocks were made of $250 \mathrm{~mm}$ long hand-insulated cable pieces. A picture of the instrumented mechanical model is shown in Fig. 15.9.

The main goals of the mechanical model were: testing various turn and ground insulation designs; practicing coil-collar assembly and simulating coil winding inside the collar structure using various insulations; and studying the stresses in the skin and in the collars after skin welding and after cool-down.

All cables around one aperture were insulated with a $0.05 \mathrm{~mm}$ thick E-glass tape with $45 \%$ overlap, all other cables were separated by $0.125 \mathrm{~mm}$ polyimide layers as turn insulation. A number of ground insulation materials, such as glass-fiber reinforced epoxy (G10), polyimide layers, and their combinations, were used with both types of cable insulation to select the most appropriate combination. The collared coil model was assembled, vacuum impregnated with CTD-101 epoxy, and the insulation tested at room temperature.

The mechanical model assembly was completed by adding the yoke, which consisted of 36 laminations, and the skin, which was welded under a press. The stresses in the skin, yoke and collars were measured and compared with the predictions of the finite element model. The mechanical model also allowed checking of all the assembly steps.

Fig. 15.9 Instrumented mechanical model before skin welding. The mechanical model includes all components of the dipole straight section, i.e., coils, collars, yoke, and skin

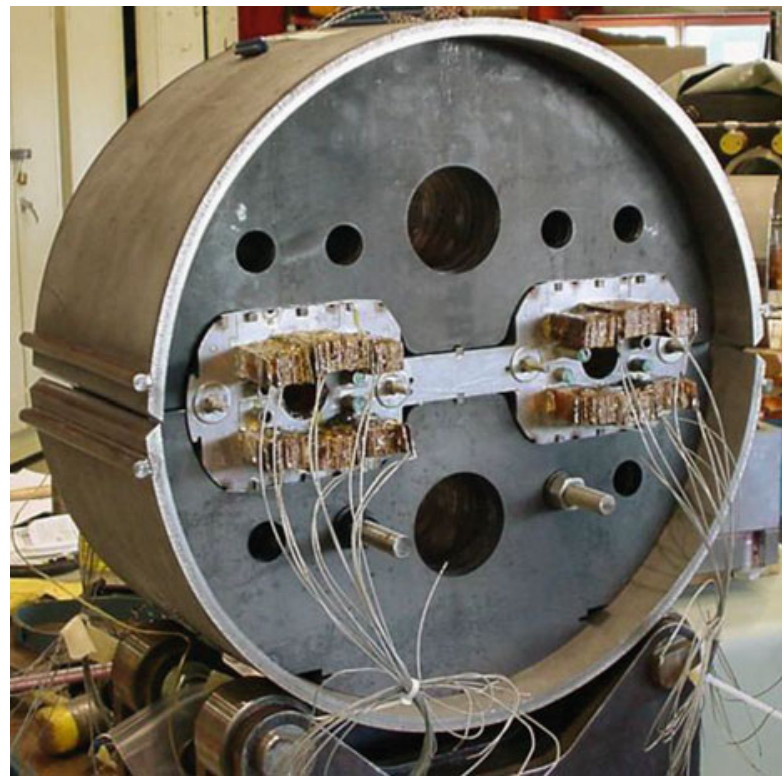




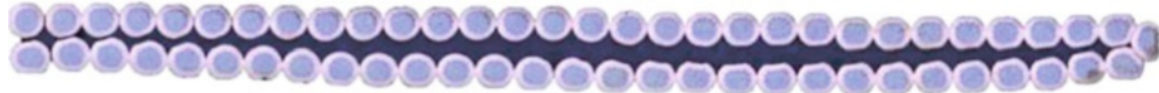

Fig. 15.10 Cross-section of the 60-strand Rutherford cable

It was found that the polyimide strip insulation is acceptable, whereas the glass tape insulation is too soft and may cause loss of coil pre-stress. The collar packs and the skin worked well, as expected. However, some modifications to the collar-yoke shim and instrumentation wires were required.

\subsubsection{HFDC Technological Model}

To test the fabrication tooling and assembly procedures, an $800 \mathrm{~mm}$ long technological model was also built using reacted $\mathrm{Nb}_{3} \mathrm{Sn}$ cable and actual magnet components.

\subsubsection{1 $\quad \mathrm{Nb}_{3} \mathrm{Sn}$ Cable}

The Rutherford cable for the technological model (Fig. 15.10) had a rectangular cross-section and was made of $60 \mathrm{Nb}_{3} \mathrm{Sn} 0.7 \mathrm{~mm}$ diameter strands. The strands were produced by IGC using the IT process developed for the ITER conductor. A $300 \mathrm{~m}$ long piece of cable for the technological model was produced at LBNL.

Two $120 \mathrm{~m}$ long pieces of cable were wound on two single-layer metallic spools together with a mica-glass tape to prevent cable sintering during heat treatment. To minimize cable bending strain during winding, the radius of the reaction spools was $180 \mathrm{~mm}$, which is a factor of two larger than the minimum radius in the coil ends. The cable was reacted in an argon atmosphere using the 4-step heat treatment schedule described above.

\subsubsection{Insulation}

Inter-turn insulation was chosen based on the test results of the mechanical model and the racetrack coils. To minimize the risk of additional cable degradation due to insulation wrapping and additional cable re-spooling during this process, the insulation was co-wound with the cable during coil winding. The insulation consisted of two tapes with the same width as the cable: a $0.163 \mathrm{~mm}$ thick pre-impregnated glass tape and a $0.075 \mathrm{~mm}$ thick polyimide tape. Both $110 \mathrm{~m}$ long glass and polyimide tapes were wound on the same spool.

The ground insulation placed around each current block comprised $0.5 \mathrm{~mm}$ thick G10 sheets and a $0.25 \mathrm{~mm}$ polyimide film. To fit the slightly wider reacted cable into the nominal collar windows, the nominal thickness of the ground insulation of the coil blocks was reduced by $0.25 \mathrm{~mm}$. 
Fig. 15.11 The copperstabilized pre-formed splice

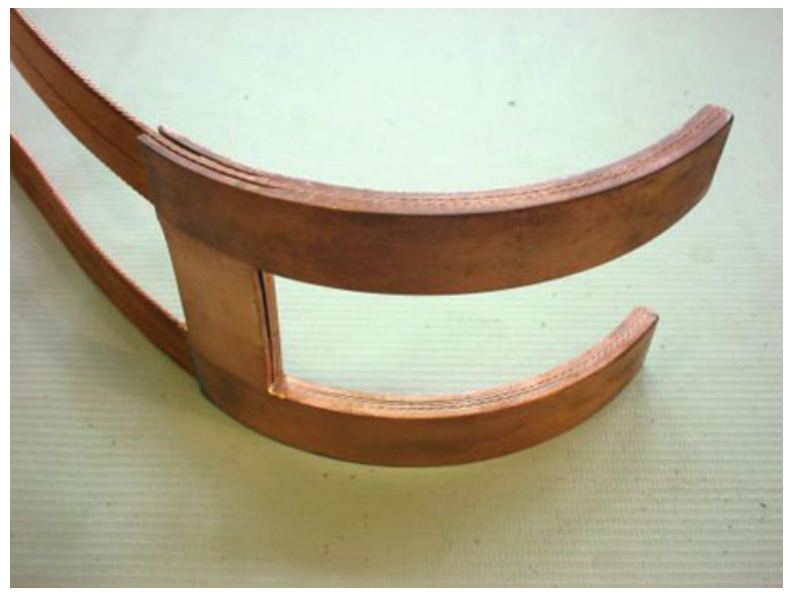

Fig. 15.12 Collar lamination packs are composed of several blocks to confine and lock the coil blocks and provide stress management

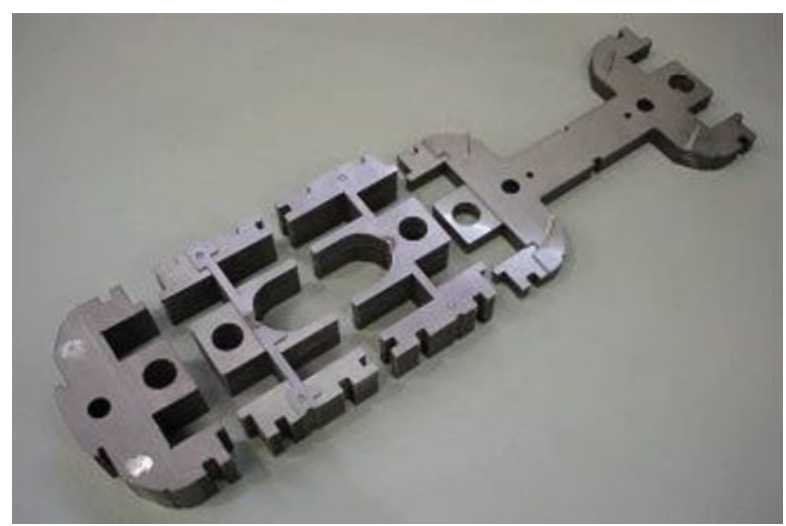

\subsubsection{Splice Joint}

The left and right coils were simultaneously wound into the support structure. To achieve the required current direction in the coils the two $\mathrm{Nb}_{3} \mathrm{Sn}$ cables were spliced before winding in a special fixture after installation of both spools on separate tensioners. The cables were joined using a U-shaped, pre-reacted multi-strand $\mathrm{Nb}_{3}$ Sn connector and copper stabilizer. The fixture also provided the desired curved shape of the splice. A copper-stabilized pre-formed splice is shown in Fig. 15.11.

\subsubsection{Coil Winding}

Each coil block was wound inside windows formed by the collar laminations (Fig. 15.12) and the stainless-steel ends, and locked in place by keys or screws. Both coils were wound and locked block-by-block (Fig. 15.13). The insulation strips were wound simultaneously with the bare cable. Four independent tensioners were 


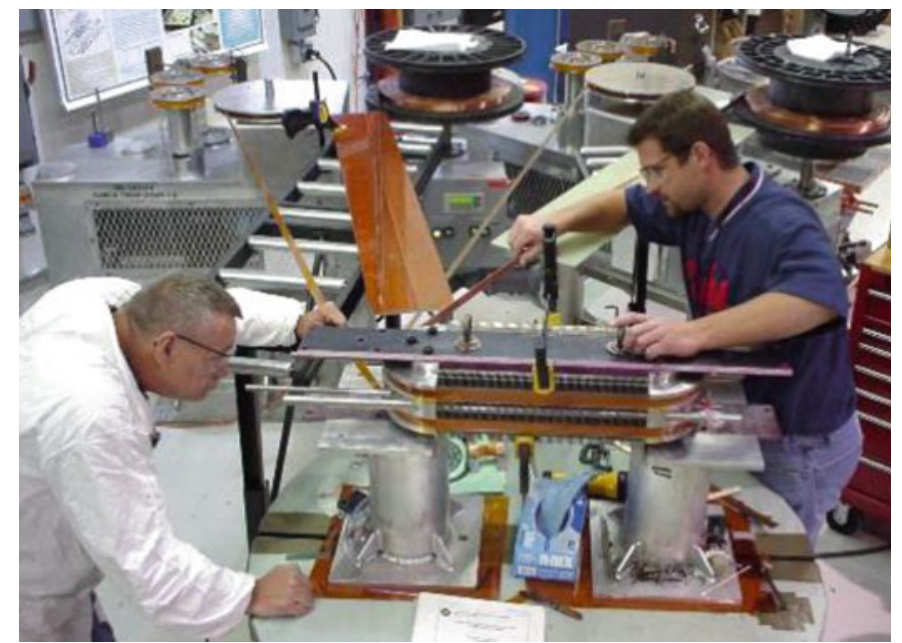

Fig. 15.13 Coil winding is performed horizontally using a rotating table. Four independent tensioners, shown in the top part of the picture, are used to apply a tension to each cable and to the insulation tapes

used to apply a tension of $90 \mathrm{~N}$ to each cable and of $135 \mathrm{~N}$ to the insulation. This approach reduced the risk of cable collapse and strand pop-out, and decreased the coil spring-back during winding.

The insulated splice was carefully inserted in the splice slot on the return end of the winding mandrel, thereby avoiding extreme cable bending. The structure formed by the collars provided the proper positioning for the insulation tapes and the cables. Side pushers were used to achieve a dense winding. The entire straight section was compressed from both sides using a special collaring fixture to insert the keys. The fixture was then removed to wind the next coil blocks. Alternated laminations were assembled in $\sim 38 \mathrm{~mm}$ long (20 laminations) packs using two pins as a base. Thin stainless-steel washers separated the laminations in the pack, and provided an adequate path for the epoxy during impregnation.

\subsubsection{Magnet Leads}

$\mathrm{Nb}_{3} \mathrm{Sn}$ cable leads were spliced with two $\mathrm{Nb}-\mathrm{Ti}$ cables and two stabilizing copper strips using a special splicing fixture. The splicing procedure was identical to that developed for the technological model. The $150 \mathrm{~mm}$ long splices were placed in the lead end block, such that about half of each splice was outside the collared coil and in direct contact with liquid helium. 


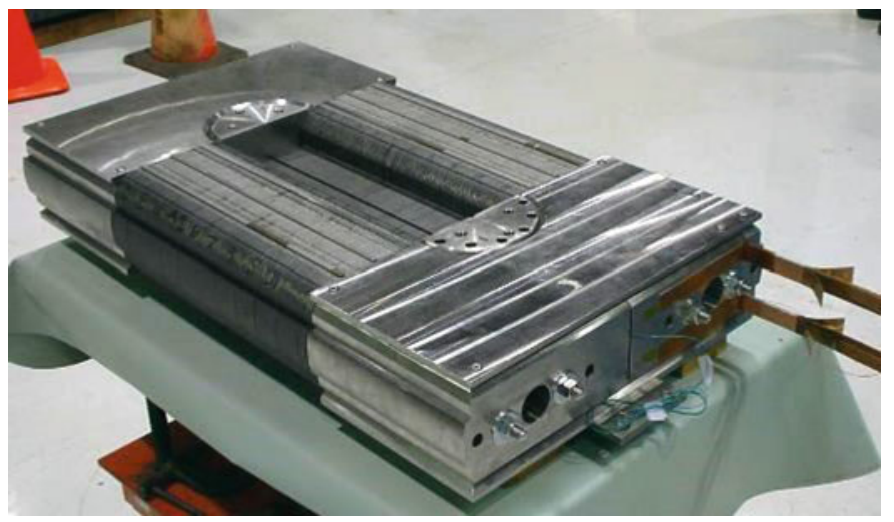

Fig. 15.14 Assembled technological model. The magnet straight section is made of a collar lamination block. The coil ends and the inter-layer splice are supported by solid stainless-steel blocks

\subsubsection{Instrumentation}

The technological model was also used to develop the magnet instrumentation plan and its technology. Instrumentation included voltage taps on each coil block and in the center of the splice box, spot-heaters, temperature sensors on each $\mathrm{Nb}_{3} \mathrm{Sn}$ cable coming out of a splice and close to each spot-heater, and quench heaters on the external side of each first block.

The fabrication of the technological model was stopped before epoxy impregnation to reuse the parts in the dipole model. The assembled technological model is shown in Fig. 15.14. The model was disassembled and the parts were used in the common-coil dipole model HFDC01.

\subsection{HFDC01 Dipole Model Fabrication}

\subsubsection{Magnet Design Features}

The 3D view of the common-coil dipole model HFDC01 is shown in Fig. 15.15. The magnet parameters are reported in Table 15.5. Based on the results from the mechanical and technological models, the necessary corrections in the design were introduced. The fabrication process for the single-layer common-coil dipole model was based on the experience gained during the technological model fabrication, with specific features as described below.

The $\mathrm{Nb}_{3} \mathrm{Sn}$ cable for HFDC01 consisted of $59 \mathrm{MJR}$ strands produced by OST. The number of strands was reduced from 60 to 59 to fit the cable into the gap in the collar packs. To avoid strand sintering during reaction, the cable was impregnated with synthetic Mobil- ${ }^{\circledR}$ oil. Two $120 \mathrm{~m}$ long cable pieces were then co-wound on 
Fig. 15.15 Common-coil dipole model

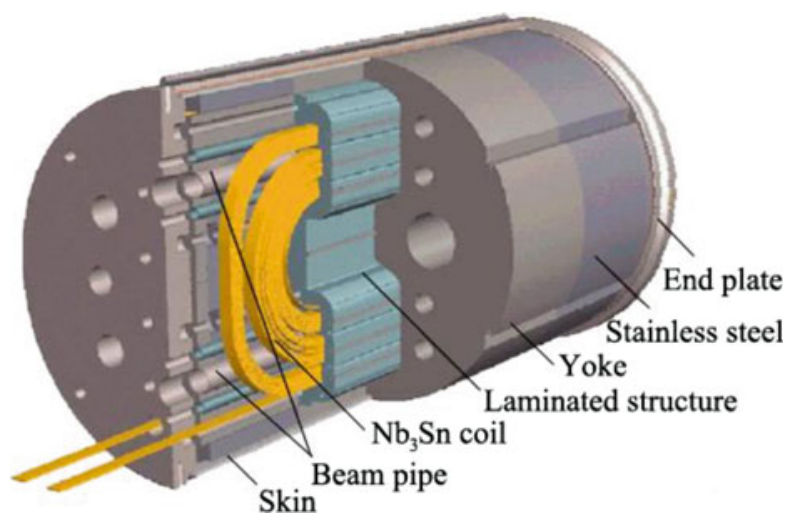

Table 15.5 Magnet design parameters

\begin{tabular}{l|l}
\hline Parameter & Value \\
\hline Maximum bore field $(\mathrm{T})$ & 10.0 \\
\hline Maximum quench current $(\mathrm{kA})$ & 23.6 \\
\hline Aperture diameter $(\mathrm{mm})$ & 40 \\
\hline Aperture separation $(\mathrm{mm})$ & 290 \\
\hline Iron yoke outer diameter $(\mathrm{mm})$ & 564 \\
\hline Iron yoke length $(\mathrm{m})$ & 0.4 \\
\hline Straight section length $(\mathrm{m})$ & 0.4 \\
\hline Stored energy at $10 \mathrm{~T}(\mathrm{~kJ} / \mathrm{m})$ & 820 \\
\hline Inductance at $10 \mathrm{~T}(\mathrm{mH} / \mathrm{m})$ & 2.95 \\
\hline
\end{tabular}

two stainless-steel spools with a $0.1 \mathrm{~mm}$ thick, $22 \mathrm{~mm}$ wide mica-glass Suritex 0822 tape to prevent sintering of the cable turns during reaction. The cable reaction was performed in an argon atmosphere inside a retort using the heat treatment cycle suggested by OST: $210{ }^{\circ} \mathrm{C}$ for $100 \mathrm{~h}, 340{ }^{\circ} \mathrm{C}$ for $48 \mathrm{~h}$, and $650{ }^{\circ} \mathrm{C}$ for $180 \mathrm{~h}$.

To monitor cable critical current, several witness samples (both round wires and strands extracted from the cable) were heat-treated on titanium-alloy barrels together with the cable. The calculated magnet short sample limit based on the witness sample data, assuming an additional $6 \%$ bending degradation of cable $I_{\mathrm{c}}$ during coil winding, was $23.3 \mathrm{kA}$, which was very close to the design value presented in Table 15.5.

Before winding, two $\mathrm{Nb}_{3} \mathrm{Sn}$ cables were spliced with two U-shaped connectors made of copper-stabilized 41-strand $\mathrm{Nb}_{3} \mathrm{Sn}$ cable, similar to the cable used in racetrack coils. The connectors were reacted using the same heat-treatment cycle as the main cable.

The cable insulation comprised two tapes: $0.16 \mathrm{~mm}$ thick pre-impregnated fiberglass tape and $0.08 \mathrm{~mm}$ thick polyimide tape. Both tapes were co-spooled on a single bobbin. The cable and the insulation were co-wound under tension into the slots of the collar structure. The inner pole blocks were wound first with a cable tension of $140 \mathrm{~N}$ and an insulation tension of $110 \mathrm{~N}$. The actual thickness of these 
first blocks was slightly larger than the design value, due to rather large variations of cable thickness. Therefore, it was decided to reduce the number of turns in each pole block from 18 to 17 and fill the remaining space with $1.27 \mathrm{~mm}$ thick G10 spacers.

The wound pair of coil blocks was gently preloaded by sets of laminated packs using a special fixture. The packs were locked together with keys. The coil ends were loaded by stainless-steel end parts with screws, rods, and nuts. The ground insulation was then installed into these new structural slots, and winding was resumed. The second and third coil blocks were wound the same way as the first ones.

The coil instrumentation was installed at the coil ends during winding, since there was no access to the coil after the collaring of each block. Each cable in the transition area between current blocks was equipped with voltage taps and temperature sensors. There were a total of 50 voltage taps, four spot-heaters, and six temperature sensors installed in the coils.

Each $\mathrm{Nb}_{3} \mathrm{Sn}$ lead cable was spliced with two $\mathrm{Nb}$-Ti cables and two stabilizing copper strips following the same splicing procedure used for the technological model. The $150 \mathrm{~mm}$ long splices were placed in the lead end block, such that about a half of each splice was outside the collared coil to have direct contact with liquid helium.

The collared coil assembly was vacuum-impregnated with epoxy in the closed mold. All internal cooling channels were plugged and sealed with High-Temperature Red RTV Silicone Gasket, and the entire outer surface of the collared coil block was treated with mold release. The block was placed into an impregnation fixture, pumped out, and filled with CTD-101 epoxy. It was then cured in an oven at $125{ }^{\circ} \mathrm{C}$ for $21 \mathrm{~h}$.

The impregnated collared coil block was shimmed and placed between the two $0.4 \mathrm{~m}$ long yoke halves. Two stainless-steel blocks were installed around each magnet end. The gap between yoke blocks at room temperature was $\sim 1.25 \mathrm{~mm}$ at the magnet body, and gradually reduced to zero at the magnet ends with the stainless-steel blocks. The skin halves were partially (50\%) hand-welded together inside the press using tack-weld and skip-weld techniques. Four final welding passes were added outside of the press after installation of the end plates.

Thick $50 \mathrm{~mm}$ end plates welded to the skin with bullets restricted the axial motion of the coil ends. Magnet ends were preloaded with bullets instrumented with strain gauges. The initial load of $5000 \mathrm{~N}$ per bullet was chosen to provide contact between the end plates and magnet ends at all temperatures. A picture of the HFDC01 dipole model is shown in Fig. 15.16.

\subsection{Magnet Test}

HFDC01 was tested in the Vertical Magnet Test Facility at FNAL in two thermal cycles (Kashikhin et al. 2004a, b). 


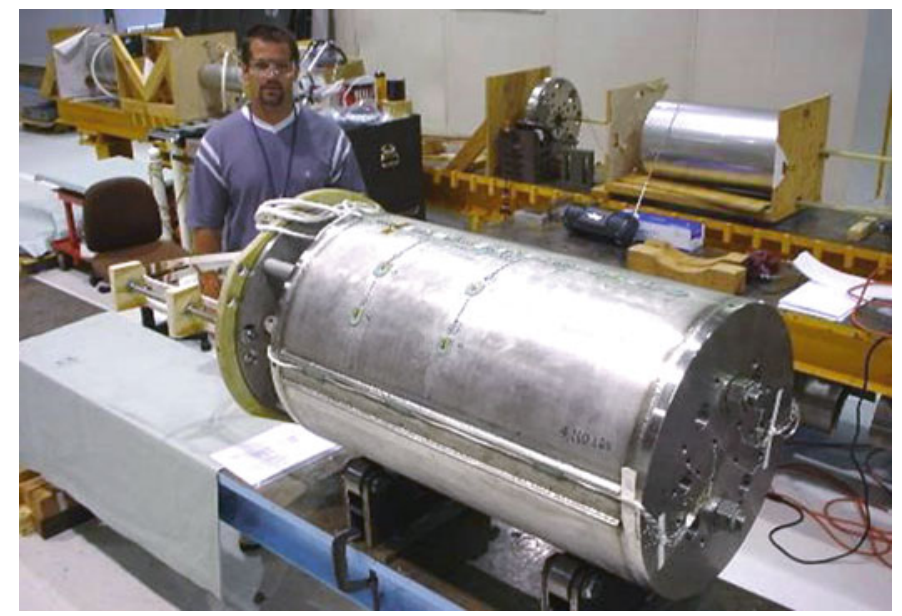

Fig. 15.16 Common-coil dipole model HFDC01 is ready for cold testing

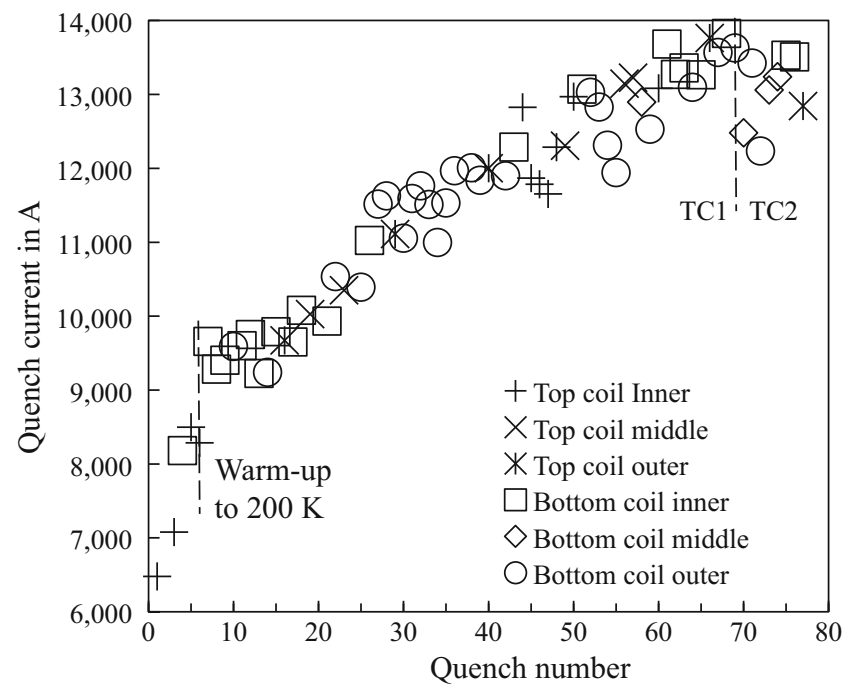

Fig. 15.17 HFDC01 training history

\subsubsection{Magnet Training}

The HFDC01 training history is plotted in Fig. 15.17. Magnet training at $4.5 \mathrm{~K}$ started at a very low current of $\sim 6.5 \mathrm{kA}$ (less than $30 \%$ of the magnet short sample limit), and was rather slow with many detraining quenches. Numerous voltage spikes were detected at low currents during the current ramp up between $2 \mathrm{kA}$ and 
a
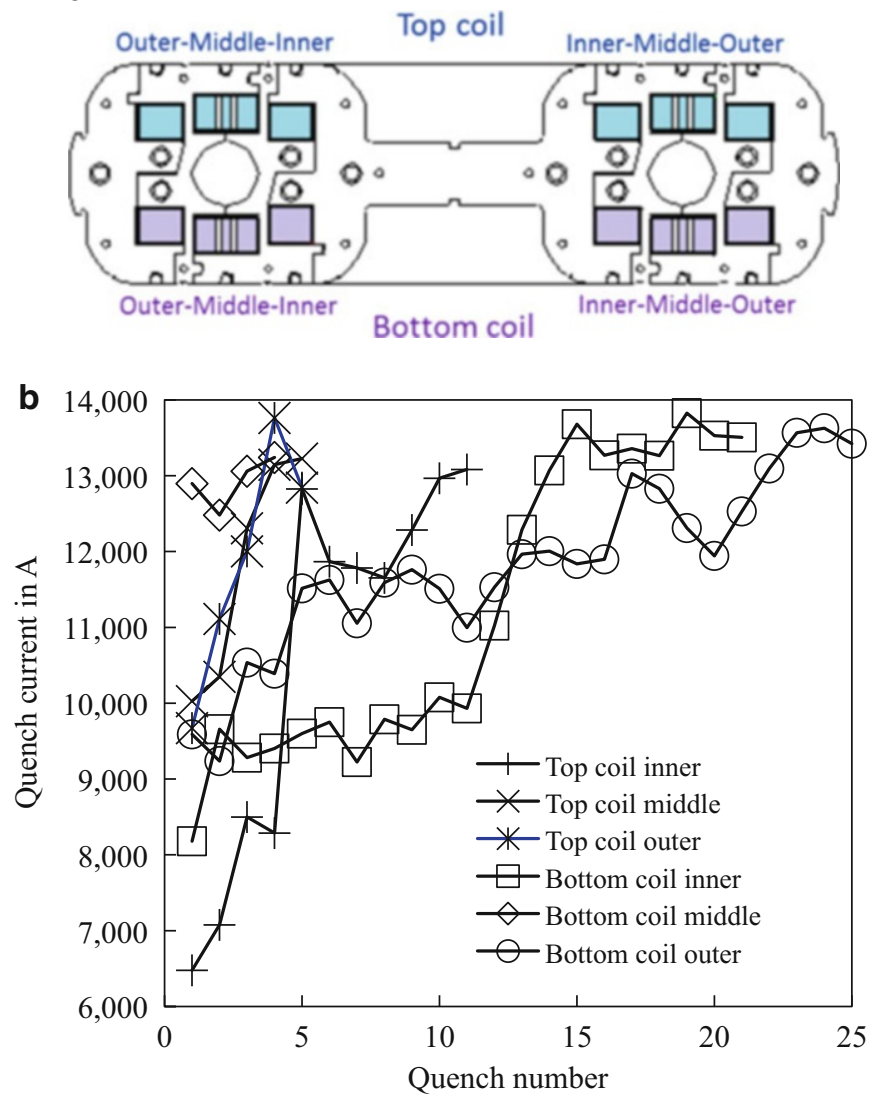

Fig. 15.18 (a) Coil block nomenclature; and (b) training quench sequence in coil blocks

$8 \mathrm{kA}$. After the first five quenches the magnet was warmed up to $200 \mathrm{~K}$. This intermediate warm-up followed by cooling down to $2.2 \mathrm{~K}$ did not impact magnet training. The magnet was warmed up to room temperature after 69 quenches. Some detraining was seen after the second thermal cycle (TC2).

The maximum quench current of $13.67 \mathrm{kA}$, which corresponds to $\sim 57 \%$ of the magnet short sample limit, was reached after 67 quenches. Even after this rather large number of quenches the magnet training was not complete. At this point magnet training was suspended.

The quench sequence in each coil block is shown in Fig. 15.18. A majority $(\sim 70 \%)$ of quenches started in the so-called "bottom coil" (this coil was at the bottom during collared coil impregnation with epoxy). These quenches were almost equally distributed between the inner and the outer coil pole blocks in this coil, and only a small number of quenches were observed in the middle (central) blocks of both coils. 


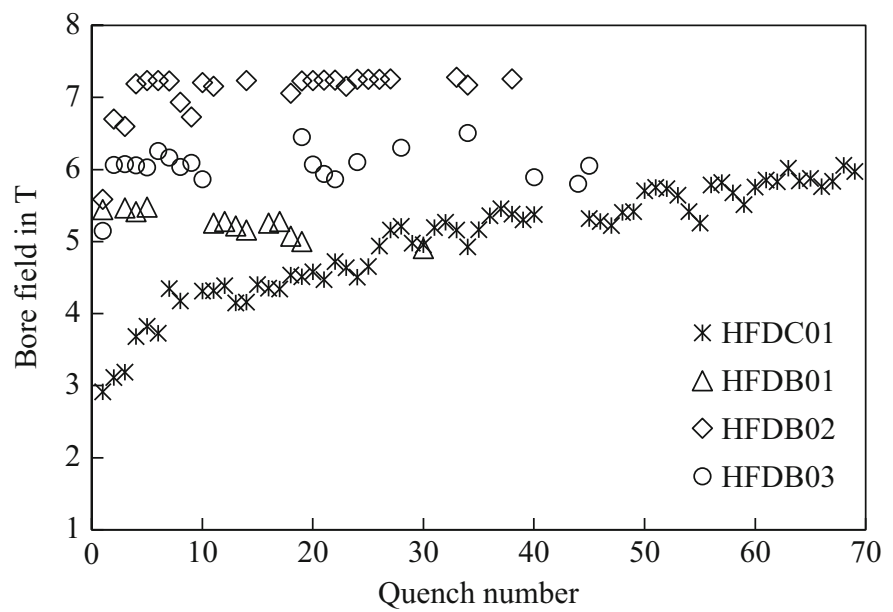

Fig. 15.19 HFDB and HFDC model training data

Although the quenches in the mid-plane blocks started at slightly higher currents (but still at around 50\% of the magnet short sample limit), there were indications that their training would also be slow (see the data for Bottom coil middle).

In the pole blocks, where the magnetic field reaches its maximum, large Lorentz force components push the turns towards the coil mid-planes, whereas in the mid-plane blocks the Lorentz force is horizontal. An insufficient coil pre-stress during assembly, or stress lost during cool-down, are consistent with the observed domination of quench origin in the coil pole blocks. The reason why the numerous quenches originated in the bottom coil remained unknown.

Bullet gauge data showed transfer of only around $15 \%$ of the axial Lorentz force to the magnet end plates. The rest of the force was transferred to the skin due to friction between the collared coil, iron yoke, and skin, and intercepted by the coil itself.

HFDC01 training data are compared in Fig. 15.19 with the training curves for FNAL R\&W single-layer racetrack magnets HFDB01, 02, and 03 described in Sect. 15.3. The maximum field reached in the HFDC01 aperture was $5.97 \mathrm{~T}$, similar to the maximum field in the gap of HFDB01 and HFDB03, and slightly lower than in HFDB02. The dipole training was, however, much longer than the racetrack magnet training. Perhaps, in addition to conductor instabilities, it was due to the more complicated dipole structure and fabrication procedure (especially the impregnation with epoxy), and to insufficient coil preload.

To address all these questions, additional tests were planned using the second dipole model HFDC02. A particularly interesting experiment would have been magnet assembly and test without coil impregnation with epoxy. It might have eliminated epoxy cracking as a source of perturbations in the coil, and improved coil cooling 
conditions. Nevertheless, the common-coil dipole program was discontinued at this stage due to a change in FNAL high field magnet program priorities.

\subsubsection{Field Quality Measurements}

Magnetic measurements were performed in both apertures in two thermal cycles using a vertical rotating coil system with a $250 \mathrm{~mm}$ long coil, $25 \mathrm{~mm}$ in diameter. The aperture closest to the leads is called "aperture I" below, whereas the other one is called "aperture II." Field harmonics are reported at $R_{\text {ref }}=10 \mathrm{~mm}$ in the magnet geometrical center. Since the HFDC01 maximum quench current was limited at $13.7 \mathrm{kA}\left(B_{\max }=5.9 \mathrm{~T}\right.$ in aperture), magnetic measurements were performed only up to $\sim 5.3 \mathrm{~T}$.

The transfer function $B / I$ and the normalized skew quadrupole $a_{2}$, which were measured in a current cycle from 0 to $12 \mathrm{kA}$ and back to 0 in the magnet body and calculated for both 2D and 3D cases, are shown in Figs. 15.20 and 15.21. The values calculated in the $3 \mathrm{D}$ case were integrated over a $250 \mathrm{~mm}$ region for a correct comparison with the measurements. The iron saturation effect is clearly seen in both plots at fields above $2.5 \mathrm{~T}$. In the $1 \mathrm{~m}$ long model this effect reduces the magnet transfer function by $3.5 \%$, and increases the absolute value of the skew quadrupole $a_{2}$ by 13 units at $5 \mathrm{~T}$ with respect to the long magnet (2D values). The $3 \mathrm{D}$ calculations agree very well with the measurements for fields above $1.5 \mathrm{~T}$. The good correlation of measurements with the 3D calculations proved that the iron saturation effect in this magnet type can be predicted and optimized by numerical simulations.

The persistent current effect in the normal sextupole $b_{3}$, measured and calculated in the magnet body, is shown in Fig. 15.22 (the geometrical components reported in Table 15.1 were subtracted from the measured data). The ramp-up branches of

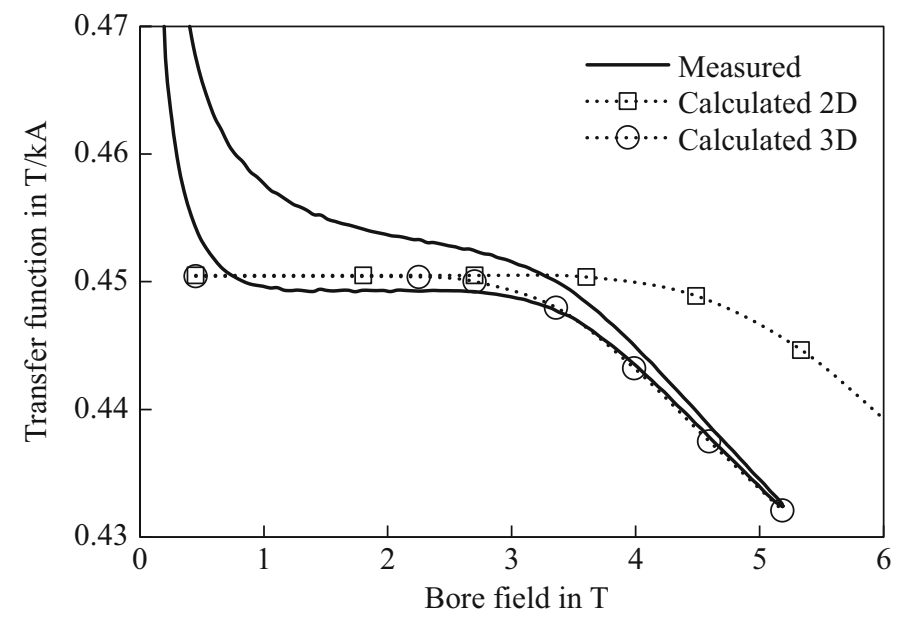

Fig. 15.20 Magnet transfer function vs. bore field 


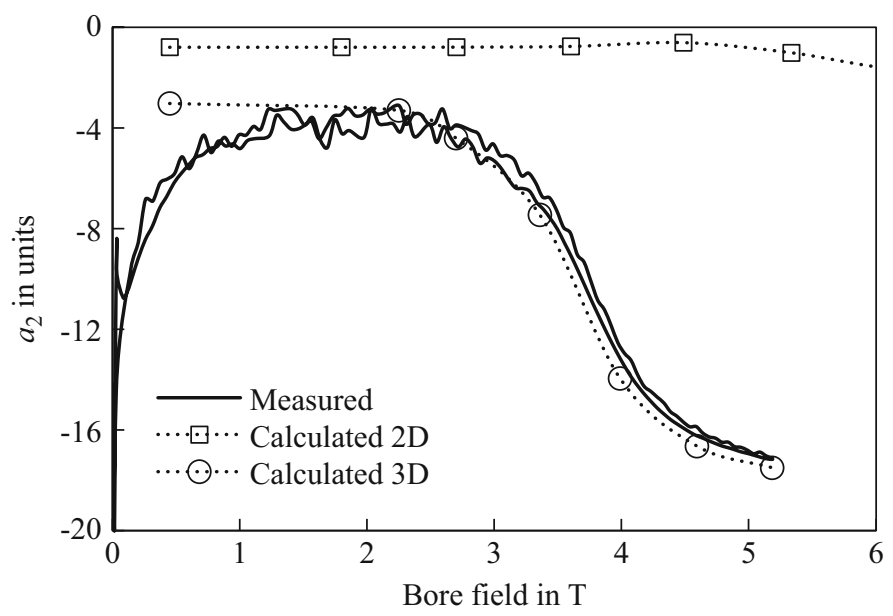

Fig. 15.21 Skew quadrupole $a_{2}$ vs. bore field

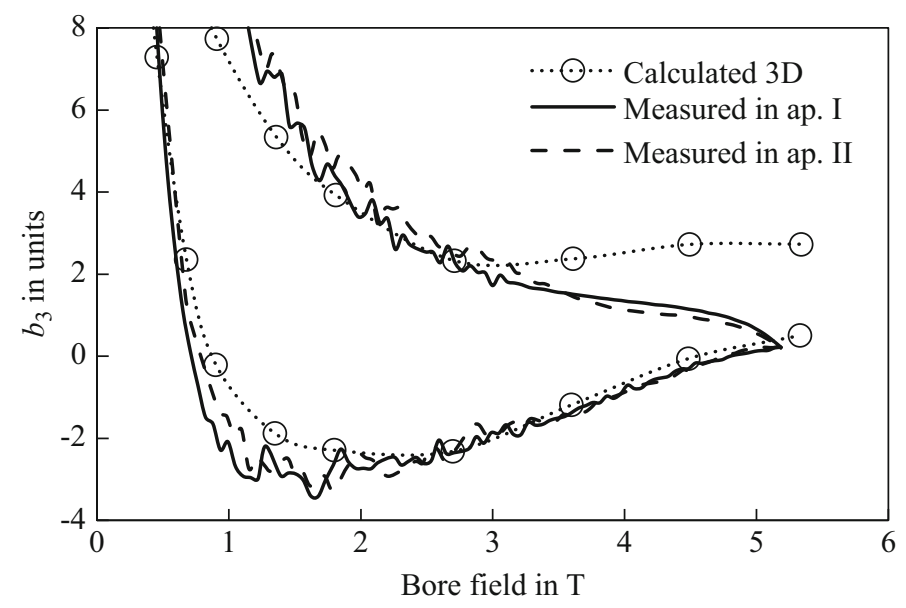

Fig. 15.22 Normal sextupole $b_{3}$ vs. bore field

both the measured and calculated curves match well at fields above $2 \mathrm{~T}$. The discrepancy in the ramp-down branches at higher fields is due to superconductor re-magnetization, which was not included in the calculations. One can clearly see the iron saturation effect in both loops, which would otherwise be symmetric with respect to the horizontal axis. The coil geometry of the single-layer magnet design described provides a rather small width for the calculated and measured loops in Fig. 15.22 (Kashikhin and Zlobin 2001b), which is a factor of 5 smaller than in the cos-theta $\mathrm{Nb}_{3} \mathrm{Sn}$ dipole models of the HFDA series (Barzi et al. 2002) (see also Chap. 7), despite the larger coil cross-section area in the common-coil magnet. 
Table 15.6 Geometrical harmonics in magnet straight section

\begin{tabular}{l|l|l|l|l|l|l}
\hline \multirow{2}{*}{$n$} & \multicolumn{2}{|l|}{ Calculated "as built" values } & \multicolumn{2}{l|}{ Measured in aperture I } & \multicolumn{2}{l}{ Measured in aperture II } \\
\cline { 2 - 7 } & $a_{n}$ & $b_{n}$ & $a_{n}$ & $b_{n}$ & $a_{n}$ & $b_{n}$ \\
\hline 2 & -3.30 & - & -3.28 & 0.16 & -3.57 & -1.26 \\
\hline 3 & - & 10.64 & 0.23 & 10.30 & -0.20 & 10.37 \\
\hline 4 & 0.03 & - & -0.35 & 0.02 & -0.66 & -0.17 \\
\hline 5 & - & 0.35 & 0.04 & 0.73 & -0.04 & 0.79 \\
\hline 6 & -0.04 & - & 0.00 & -0.01 & 0.01 & 0.01 \\
\hline 7 & - & -0.08 & 0.00 & -0.06 & -0.00 & -0.05 \\
\hline 8 & -0.00 & - & \multicolumn{6}{l}{ Used for the centering correction } \\
\hline 9 & - & -0.01 & -0.00 & -0.03 & -0.00 & -0.03 \\
\hline
\end{tabular}

Large fluctuations of $b_{3}$ (Fig. 15.22) as well as voltage spikes were seen during HFDC01 tests at low currents. These results are consistent with the large flux jump instabilities observed in the $\mathrm{Nb}_{3} \mathrm{Sn}$ MJR54/69 wires used in this magnet.

The harmonic ramp-rate dependence was measured in three consequent current cycles up to $12 \mathrm{kA}$, with current ramp rates of $20 \mathrm{~A} / \mathrm{s}, 40 \mathrm{~A} / \mathrm{s}$, and $80 \mathrm{~A} / \mathrm{s}$. The dependence of the field harmonics on the current ramp rate was very small. The absence of eddy currents in the cable was related to the rather large inter-strand resistance, produced during the cable reaction with synthetic oil without transverse pressure on the cable (Ambrosio et al. 2004b).

To evaluate the dynamic effects at injection-like conditions, field measurements were performed at a current plateau of $2.4 \mathrm{kA}(B=1.125 \mathrm{~T})$ of 30 min duration, following a pre-cycle up to $12 \mathrm{kA}$. The measured harmonic decay on the current plateau was very small, less than 0.3 unit, with respect to the $b_{3}$ decay in $\mathrm{Nb}$ - $\mathrm{Ti}$ accelerator magnets. This result agreed well with measurements of dynamic effects in FNAL $\mathrm{Nb}_{3} \mathrm{Sn}$ cos-theta dipole models of the HFDA series (Barzi et al. 2002).

The geometrical harmonics were defined as average values between up and down current ramps at $5 \mathrm{kA}$. A comparison of measured and calculated values in the 3D case for the as-built geometry harmonics is presented in Table 15.6. For a correct comparison, the calculated harmonics were integrated over the probe length of $250 \mathrm{~mm}$. There is an excellent correlation between the calculated and measured geometrical harmonics in the magnet straight section. The integrated harmonics in the magnet return end are also consistent with the calculations. It confirmed the high efficiency of the coil support structure for maintaining the nominal coil geometry, and thereby the field quality during magnet assembly and operation. 


\subsection{Conclusion}

A single-layer common-coil dipole magnet was developed at FNAL for a VLHC. The magnet was designed to provide $10 \mathrm{~T}$ nominal field of accelerator quality in two $40 \mathrm{~mm}$ diameter apertures at an operating temperature of $4.5 \mathrm{~K}$. To produce the nominal operating field of $10 \mathrm{~T}$ with $15 \%$ margin, the design described needs $\mathrm{Nb}_{3} \mathrm{Sn}$ wires with a high $J_{\mathrm{c}}(12 \mathrm{~T}, 4.2 \mathrm{~K})$ of $3 \mathrm{kA} / \mathrm{mm}^{2}$.

The magnet has several innovative design and technological features, such as a single-layer coil, a $22 \mathrm{~mm}$ wide 60 -strand Rutherford-type cable made of $0.7 \mathrm{~mm}$ $\mathrm{Nb}_{3} \mathrm{Sn}$ wires, and a stainless-steel coil support structure reinforced by horizontal bridges inserted between coil blocks. Both the left and right coils were wound simultaneously into the collar structure and then impregnated in situ with epoxy.

The magnet was designed to use the $\mathrm{R} \& \mathrm{~W}$ technique (i.e., the cable is reacted before coil winding). Various aspects of this technique were studied using mechanical and technological models and a series of single-layer racetrack magnets. Three $1 \mathrm{~m}$ long racetracks (HFDB01-03) and one common-coil dipole model (HFDC01) based on reacted cables were fabricated and tested from 2001 to 2003. All magnets survived the complicated fabrication process and reached $60-75 \%$ of the expected short sample limit. A good, well-understood field quality was achieved in both apertures of the HFDC01 dipole model. However, the dipole model and all the racetrack magnets showed large quench current degradation, and the dipole model also had very slow training. There are several indications that this performance was partially caused by flux jump instabilities in the $\mathrm{Nb}_{3} \mathrm{Sn}$ composite wires used at the time. To further explore the potential of the common-coil dipole design and the $\mathrm{R} \& \mathrm{~W}$ technology for accelerator magnets, more efforts are required.

\section{References}

Ambrosio G, Kashikhin VV, Limon PJ et al (2000a) Conceptual design study of high field magnets for very large hardon collider. IEEE Trans Appl Supercond 10(1):310-313. https://doi.org/10. $1109 / 77.828236$

Ambrosio G, Andreev N, Barzi E et al (2000b) Study of the react and wind technique for a $\mathrm{Nb}_{3} \mathrm{Sn}$ common coil dipole. IEEE Trans Appl Supercond 10(1):338-341. https://doi.org/10.1109/77. 828243

Ambrosio G, Andreev N, Barzi E et al (2001) Development of react and wind common coil dipoles for VLHC. IEEE Trans Appl Supercond 11(1):2172-2175. https://doi.org/10.1109/77.920288

Ambrosio G, Andreev N, Barzi E et al (2002a) R\&D for a single-layer $\mathrm{Nb}_{3} \mathrm{Sn}$ common coil dipole using the react-and-wind fabrication technique. IEEE Trans Appl Supercond 12(1):39-42. https://doi.org/10.1109/tasc.2002.1018347 
Ambrosio G, Andreev N, Barzi E et al (2002b) Development and test of a $\mathrm{Nb}_{3} \mathrm{Sn}$ racetrack magnet using react and wind technology. In: Breon S, DiPirro M, Glaister D et al (eds) Advances in cryogenic engineering: proceedings of the cryogenic engineering conference vol 47A. American Institute of Physics, Melville, NY, AIP Conf Proc 613, pp 329-336

Ambrosio G, Andreev N, Barzi E et al (2003) Fabrication and test of a racetrack magnet using pre-reacted $\mathrm{Nb}_{3} \mathrm{Sn}$ cable. IEEE Trans Appl Supercond 13(2):1284-1287. https://doi.org/10. $1109 /$ tasc. 2003.812647

Ambrosio G, Andreev N, Barzi E et al (2004a) Design modifications, fabrication and test of HFDB03 racetrack magnet wound with pre-reacted $\mathrm{Nb}_{3} \mathrm{Sn}$ Rutherford cable. In: Waynert J, Barclay J, Breon $\mathrm{S}$ et al (eds) Advances in cryogenic engineering: transactions of the international cryogenic engineering conference-CEC, vol 49A. AIPC, Anchorage, Alaska, 22-26 September 2003. American Institute of Physics, Melville, NY, AIP Conf Proc 710, p 767

Ambrosio G, Barzi E, Chichili D et al (2004b) Measurement of inter-strand contact resistance in epoxy impregnated $\mathrm{Nb}_{3} \mathrm{Sn}$ Rutherford cables. In: Balachandran UB, Adams M (eds) Advances in cryogenic engineering: transactions of the international cryogenic engineering conferenceCECAIP, Anchorage, Alaska, 22-26 September 2003, vol 711. American Institute of Physics, Melville, New York, pp 828-835

Barzi E, Carcagno R, Chichili D et al (2002) Field quality of the Fermilab $\mathrm{Nb}_{3} \mathrm{Sn}$ cos-theta dipole models. In: Terence G (ed) Proceedings of the 8th European particle accelerator conference (EPAC 2002), Paris, France, 3-7 June 2002. European Physical Society, Geneva, pp 2403-2405

Bauer P, Ambrosio G, Andreev N et al (2001) Fabrication and testing of Rutherford-type cables for react and wind accelerator magnets. IEEE Trans Appl Supercond 11(1):2457-2460. https://doi. org/10.1109/77.920360

Chichili DR, Arkan TT, Ozelis JP et al (2000) Investigation of cable insulation and thermomechanical properties of epoxy impregnated $\mathrm{Nb}_{3} \mathrm{Sn}$ composite. IEEE Trans Appl Supercond 10(1):1317-1320. https://doi.org/10.1109/77.828478

Fermilab (2001) Design study for a staged Very Large Hadron Collider. Fermilab-TM-2149, 4 June. http://lss.fnal.gov/archive/test-tm/2000/fermilab-tm-2149.pdf

Gupta R (1997) A common coil design for high field 2-in-1 accelerator magnets. In: Comyn M, Craddock MK, Reiser M et al (eds) Proceedings of the 1997 particle accelerator conference, Vancouver, 12-16 May 1997. IEEE, Piscataway/New York, pp 3344-3346

Kashikhin VV, Zlobin AV (2001a) Magnetic designs of 2-in-1 $\mathrm{Nb}_{3} \mathrm{Sn}$ dipole magnets for VLHC. IEEE Trans Appl Supercond 11(1):2176-2179. https://doi.org/10.1109/77.920289

Kashikhin VV, Zlobin AV (2001b) Correction of the persistent current effect in $\mathrm{Nb}_{3} \mathrm{Sn}$ dipole magnets. IEEE Trans Appl Supercond 11(1):2058-2061. https://doi.org/10.1109/77.920260

Kashikhin VS, Ambrosio G, Andreev N et al (2004a) Development and test of single-layer common coil dipole wound with reacted $\mathrm{Nb}_{3} \mathrm{Sn}$ cable. IEEE Trans Appl Supercond 14(2):353-356. https://doi.org/10.1109/tasc.2004.829128

Kashikhin VS, Andreev N, DiMarco J et al (2004b) Field quality measurements of Fermilab $\mathrm{Nb}_{3} \mathrm{Sn}$ common coil dipole model. IEEE Trans Appl Supercond 14(2):287-290. https://doi.org/10. 1109/tasc. 2004.829087

Novitski I, Andreev N, Ambrosio G et al (2001) Design and mechanical analysis of a single-layer common coil dipole for VLHC. IEEE Trans Appl Supercond 11(1):2276-2279. https://doi.org/ $10.1109 / 77.920314$

Ohira S, Nishijima S (2000) Effect of impregnating material failure on stability of superconducting magnet analyzed by wire dynamics simulation. IEEE Trans Appl Supercond 10(1):665-668 . https://doi.org/10.1109/77.828321

Russenschuck S (1995) A computer program for the design of superconducting accelerator magnets. In: 11th annual review of progress in applied computational electromagnetics, Monterey, 20-24 March 1995, vol 1, pp 366-377; CERN AT/95-39 
Sabbi G, Ambrosio G, Andreev N et al (2000) Conceptual design of a common coil dipole for VLHC. IEEE Trans Appl Supercond 10(1):330-333. https://doi.org/10.1109/77.828241

Zlobin AV, Kashikhin VV, Barzi E et al (2006) Effect of flux jumps in superconductor on $\mathrm{Nb}_{3} \mathrm{Sn}$ accelerator magnet performance. IEEE Trans Appl Supercond 16(2):1308-1311. https://doi.org/ $10.1109 /$ tasc.2006.870557

Open Access This chapter is licensed under the terms of the Creative Commons Attribution 4.0 International License (http://creativecommons.org/licenses/by/4.0/), which permits use, sharing, adaptation, distribution and reproduction in any medium or format, as long as you give appropriate credit to the original author(s) and the source, provide a link to the Creative Commons licence and indicate if changes were made.

The images or other third party material in this chapter are included in the chapter's Creative Commons licence, unless indicated otherwise in a credit line to the material. If material is not included in the chapter's Creative Commons licence and your intended use is not permitted by statutory regulation or exceeds the permitted use, you will need to obtain permission directly from the copyright holder. 